\title{
¿FEMINICIDIO DE AFRODESCENDIENTES EN MÍXICO? Lo que no se nombra no existe
}

\author{
IS THERE AFRODESCENDANT FEMINICIDE IN MEXICO? \\ What is not named does not exist \\ FEMINICIDIO DE AFRODESCENDENTES NO MEXICO? \\ O que não tem nome não existe
}

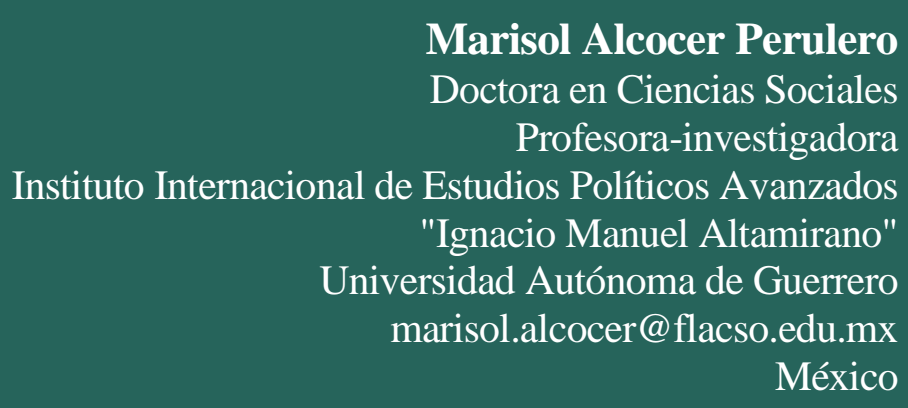

\section{Resumen}

La intersección entre el racismo y sexismo ha sido definitoria en diversos trabajos académicos para analizar el feminicidio. Sin embargo, en México, aunque se asume que esta relación se replica, existe un vacío (cuantitativo y cualitativo) para identificar cómo pasa en el caso de las mujeres afromexicanas. El objetivo de este artículo es reflexionar y describir la invisibilización histórica de la población afrodescendiente en su dimensión de la violencia contra las mujeres que culmina en asesinato por razones de género: el feminicidio. Me centro particularmente en el estado de Guerrero, pero en adición, busco aportar evidencia de lo que sucede en todo el país. Me centro en papel de tres actores: los agentes del Estado como principal institución responsable de generar información estadística sobre este fenómeno; las organizaciones de la sociedad civil organizada contra la 
violencia de género; por último, reflexiono sobre el papel de la prensa y la forma en cómo ha sido una herramienta para visibilizar el feminicidio.

Palabras clave: Feminicidio, afromexicanas, feminismo.

\begin{abstract}
The intersection between racism and sexism has been defined in various academic works to analyze feminicide. However, in Mexico, although it is assumed that this relationship is $r$ perpetuated, there is a gap (quantitative and qualitative) to identify how it happens in the case of Afro-Mexican women. The objective of this article is to reflect on and describe the historical invisibility of the Afro-descendant population in the dimension of violence against women that culminateds in gender-based murder: feminicide. I focus particularly on the state of Guerrero, but additionally, I seek to provide evidence of what is happening throughout the country. I focus on the role of three actors: the Agents of the State as the director responsible for generating statistical information on this phenomenon; also in organized civil society organizations against gender violence; last but not least, a reflection on the role of the press and how it has become a tool to make feminicide visible.
\end{abstract}

Keywords: femicide, afromexican, afrodescendant, feminism.

\title{
Resumo
}

A intersecção entre racismo e sexismo tem se definido em diversos trabalhos acadêmicos de análise do feminicídio. No entanto, no México, embora se presuma que esta relação é repetida, há um vazío (quantitativo e qualitativo) para identificar como é que acontece no caso das mulheres afromexicanas. O objetivo deste artigo é refletir e descrever a invisibilidade histórica da população afrodescendente em sua dimensão de violência contra a mulher que culmina em assasinato por motivos de gênero: o feminicídio. Eu me concentro principalmente no estado de Guerrero, mas, além disso, procuro fornecer evidências do que está acontecendo em todo o país. Concentro-me no papel de três atores: os agentes do Estado como principal instituição responsável pela geração de informação estatística sobre este fenômeno; organizações da sociedade civil organizada contra a violência de gênero; enfim, reflito sobre o papel da imprensa e como ela tem sido uma ferramenta para tornar o feminicídio visível.

Palavras-chave: Feminicídio, Afromexicana, feminismo 


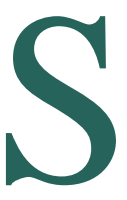

oy de las feministas que ha participado

en la sistematización del homicidio de mujeres $\mathrm{y}$ feminicidio en Guerrero ${ }^{1}$. Desde 2005, siendo aún estudiante universitaria, me integré al Observatorio de Violencia Contra las Mujeres de Guerrero, (de aquí en adelante, OVICOM) "Hannah Arendt", fundado y coordinado por la académica-feminista Rosa Icela Ojeda Rivera. El OVICOM desde su creación ha dado seguimiento a los asesinatos de mujeres, perpetrados en el estado de Guerrero, México, desde el 2005 a la fecha. La fuente de información principal del observatorio han sido los diversos medios de circulación estatal en el estado, y en algunos años ha podido hacer un trabajo comparativo y complementario con los registros administrativos de otras instituciones encargadas de la procuración e impartición de justicia (OJEDA, 2017).

En esos primeros años de mi formación en el observatorio, noté que no se daba cuenta del feminicidio de mujeres racializadas en general, y de las mujeres afrodescendientes, negras o morenas en particular $^{2}$. Esta apreciación me permitió

\footnotetext{
${ }^{1}$ Guerrero es una de las 32 entidades que conforman a los Estados Unidos Mexicanos. Está ubicado en el pacífico. En esta entidad se encuentra uno de los puertos más famosos de México: Acapulco.

${ }^{2}$ Las formas de autoidentificarse varían. De acuerdo con Hoffman y Lara (2012) Entre las principales denominaciones se encuentran "afromexicanos", "afromestizos" y "negros" (Pág. 40). Aunque el término que lleva la palabra "mestizo", ya está es desuso.
}

recopilar a lo largo de mis experiencias de investigación, evidencia suficiente sobre un proceso de invisibilización histórica, tanto del feminicidio, como de los contextos de las mujeres racializadas dentro de él.

Este antecedente da paso a escribir este ensayo en torno a la invisibilización histórica en México del feminicidio de mujeres racializadas. Al pretender desarrollar esta inquietud, lo primero que me llamó la atención fue la notable ausencia de datos confiables por parte de los agentes del Estado encargados de la procuración de justicia, como la antigua Procuraduría, actual Fiscalía General del Estado, la cual era la responsable de generar información respecto al feminicidio. Esa falta de datos fiables responde a la disputa e invisibilidad del feminicidio como fenómeno, donde la negación era la característica principal, tal y como lo muestro más adelante. En este sentido, el análisis feminista -en el cual me incluyo- ha interpelado al Estado para el reconocimiento del feminicidio como problema, aunque en un principio, sin considerar visibilizar a las mujeres racializadas afrodescendientes en México. En este texto, hablo de feminicidio y homicidio

No obstante, el término afromexicano/a, tanto como los que apelan a elementos de la cotidianidad que hacen referencia a diferencias físicas, siguen en el discurso: negro/a, moreno/a (Castillo, 2016). Por ello, en el transcurso de este texto usaré los términos "afromexicano/a, negro/a, o moreno/a, como categorías necesarias de distinguirse, pero que confluyen en algún punto en torno a la identidad. 
de mujeres reconociendo que existe una diferencia entre ambos conceptos. No todo asesinato de mujer es feminicidio, mientras no sea motivado por razones de género (RADFORD, 2006). La premisa de este trabajo es que el feminicidio obedece "a un dispositivo de género" (SEGATO, 2014) que, sin embargo, requiere entender los contextos de violencias para desuniversalizar la idea del sujeto mujer. Cabría entonces preguntarnos ¿Cómo podemos comenzar a trascender la idea de que el género es el único marcador que las hace vulnerable al ejercicio de la violencia extrema que culmina en asesinato? El análisis interseccional puede dar algunas líneas para reflexionar respecto a esos contextos diversos, y pensar en los impactos de las estructuras del poder patriarcal en las muertes y asesinatos de mujeres de distintos grupos étnicos. Por ejemplo, Brasil es un caso paradigmático respecto a los efectos de la racialización, pues se ha mostrado un efecto diferenciado de Ley contra la violencia Maria da Penha, ya que desde su promulgación el número de homicidios de mujeres afrodescendientes/negras ha aumentado, mientras que el porcentaje de mujeres blancas ha decrecido (WAISELFISZ, 2015) ${ }^{3}$. Un acercamiento de este tipo en México es imposible si se toma en cuenta la forma en cómo están construidos los datos,

\footnotetext{
3 "Las tasas de homicidios de mujeres blancas cayeron 11.9\%: de 3.6 por cada 100 mil mujeres blancas, en 2003, a 3.2 en 2013. En contraste, las tasas de mujeres negras aumentaron
}

actualmente. Por ejemplo, en los Registros de Mortalidad se puede registrar la categoría de si la víctima de homicidio -feminicidio o nohabla o no lengua indígena, aunque desde 2012 de acuerdo con DATA CIVICA:

[...] el porcentaje de los registros para los que no hay información disponible sobre esta característica oscila entre el $57 \%$ y el $37.5 \%$ del total... Esto implica que hasta el día de hoy simplemente no sabemos cómo afecta la violencia homicida a las personas indígenas del país" (2019: p. 37).

El habla de la lengua indígena es apenas una dimensión, esta situación se complejiza todavía más, cuando la lengua no es indicador de la pertenencia étnica, tal como sucede con la población afromexicana.

Mas allá de los datos oficiales, diversas feministas académicas han aportado elementos para la reflexionar las complejas interacciones entre racismo y sexismo (RADFORD, 2006). En este sentido, las propuestas de Julia Monárrez dan elementos para pensar en la necesidad de un análisis desde la clase social para superar algunos marcos feministas que privilegian el género en detrimento de variables como clase social y otras importantes categorías de opresión (MONÁRREZ, 2002; 2009).

$19.5 \%$, en el mismo período, de 4.5 a 5.4 por cada 100 mil" (Waiselfisz, 2015: 31[traducción propia]). 
Por su parte, Lagarde sugiere que la visión sociológica y antropológica analiza los crímenes de Ciudad Juárez en el marco fronterizo "y ponderan la situación económica incluso de clase y de poder, tanto de las mujeres víctimas como de los victimarios y de la zona, así como el impacto del Tratado de Libre Comercio y las maquilas en el crecimiento desorganizado socialmente, la marginación y la pobreza" (2011, p. 212). Por su parte, Segato (2006), al identificar la clase como una variable importante del feminicidio, sugiere que ésta tiene que ser considerada tanto para las víctimas como para los victimarios, y sugiere que son las clases privilegiadas que se benefician con los crímenes de Ciudad Juárez conformando lo que ella llama como hermandad mafiosa. En la misma línea, Laurenzo (2012) propone que el análisis del género en el femicidio tiene que considerar otros elementos, como la etnia de la víctima, la violencia ambiental o el desarraigo social.

En síntesis, existen marcadores de opresión que condicionan las vidas y asesinatos de mujeres: mujeres precarias, racializadas, insertas en un sistema racista y sexista. Por lo tanto, urge voltear la mirada analítica al respecto, porque se sabe poco del feminicidio de mujeres afrodescendientes en México ${ }^{4}$.

\footnotetext{
${ }^{4}$ Aunque a nivel comunitario Alcocer (2017) reflexiona los significados y cómo es ejercida la violencia contra las mujeres en la dimensión física, sexual y feminicidio
}

Por lo anterior, para alcanzar el objetivo de describir la invisibilización histórica del feminicidio de las mujeres racializadas afrodescendientes en México, mi reflexión la posiciono desde una mirada cualitativa y desde el enfoque feminista e interseccional. Muestro cómo ha sido interpretado el feminicidio de mujeres afrodescendientes en Guerrero tanto por los agentes del Estado, como por las organizaciones feministas y la prensa. Tomo como referente empírico artículos de opinión o reportajes sobre el tema de los homicidios dolosos y de feminicidio en Guerrero. Complemento la información con entrevistas realizadas a agentes del Estado encargados de la procuración de justicia, principalmente de la Fiscalía General del Estado, en la entidad.

Cabe recordar que en torno al feminicidio se suelen construir diversos discursos y éste no es neutro. Sobre las víctimas de feminicidio $\mathrm{y}$ homicidio se construyen representaciones que las sancionan moralmente y culpabilizan del asesinato por tener comportamientos alejados de los dictados de la normatividad del género de "buena mujer" (ALCOCER, 2014). Esto nos lleva a cuestionarnos sobre ¿quiénes son consideras como las verdaderas víctimas de feminicidio? y ¿quiénes son las mujeres agresoras y propiciatorias de su asesinato?

en dos comunidades con población mayoritariamente Afromexicana. 
Los discursos que estigmatizan a las mujeres a veces son compartidos por los agentes del Estado, que si bien tienen impactos es el plano simbólico-discursivo, también tienen efectos materiales que se ejemplifican en la falta de investigación, impunidad, o naturalización del feminicidio.

$\mathrm{Al}$ respecto, existe todo un cuerpo de literatura que da cuenta de cómo el Estado ha invisibilizado el feminicidio. Estudios como el de Monárrez (2009) muestra la estrategia discursiva del Estado y sus agentes e instituciones para mantener la manipulación y la impunidad del feminicidio. En la misma línea analítica, Martínez (2011) analiza el discurso en torno al feminicidio y "los efectos del lenguaje", donde el hilo conductor gira en torno a los elementos para repensar el feminicidio, a partir de la reflexión de los efectos prácticos.

Este panorama lleva también a cuestionarnos sobre ¿Cuáles eran las intencionalidades y efectos de esos discursos, las formas legítimas y en contrapartida las no aceptadas para referirse a los asesinatos de mujeres en Guerrero por razones de género?, ¿cuál es la construcción de sentido que se dio en torno al feminicidio en Guerrero en un primer momento por parte de los agentes del Estado y las organizaciones de la sociedad civil?¿cuál es la importancia que tiene el discurso para comprender el feminicidio en general y en particular de las mujeres afromexicanas, negras o morenas? Esto es a lo que se busca reflexionar en este trabajo.

En primer lugar, es necesario entender que el discurso hace referencia a sistemas de representación que regulan lo que se puede hacer con el lenguaje en una situación y un contexto determinados, (LÓPEZ y PÉREZ, 2009). El autor de referencia indiscutible es Michel Foucault para quien el discurso no es simplemente aquello que traduce las luchas, los sistemas de dominación, "sino aquello por lo que, y por medio de lo cual se lucha, aquel poder del que quiere uno adueñarse" (1992, p.6). Identifica al discurso como medio y como fin, es poder fundamental porque con él se representa la realidad, se dice la verdad más conveniente, y se persuade para hacer creer esa verdad. En la misma línea teórica posestructuralista, Joan Scott sugiere que "Un discurso no es un lenguaje ni un texto, sino una estructura histórica, social e institucionalmente específica de enunciados, términos, categorías y creencias (SCOTT, 1992, p. 87).

El discurso como categoría es útil para entender la estructura social y las creencias respecto a la violencia que culmina en el asesinato de las mujeres, cómo enuncian a las víctimas, si éste las responsabiliza, y /o las estigmatiza; a la par, esta categoría permite entender la invisibilización del feminicidio de mujeres racializadas en el marco de una estructura histórica que ha borrado a la población afrodescendiente, 
morena o negra en Guerrero y México.

La herramienta analítica en la que me apoyo en este texto es el Análisis Crítico del Discurso, para reflexionar la invisibilización como una forma de discriminación, que trae como resultado opacidad social, donde los agentes del Estado forman parte de la élite a través de la generación de información e investigación

\begin{abstract}
"[...]participan en las tomas de decisión política concernientes a grupos étnicos minoritarios, escriben informes, o investigan, tienen acceso a los mass media y producen el saber y las creencias que influyen en la función y el cambio de opinión de la gran mayoría de la población" (VAN DIJK, 1993, p. 107).
\end{abstract}

La invisibilización también la identifico en la construcción de la información que realizan las mujeres organizadas feministas; $y$, en la prensa. Por lo que sostentgo que existe un vacío en la construcción de significado del feminicidio en Guerrero que dé cuenta de la situación de mujeres racializadas.

Reflexiono a Guerrero como un caso paradigmático (FLYVBJERG, 2004), dado que pone "de relieve las características generales de las sociedades en cuestión" (P. 47), en este caso a la población afromexicana, al ser la entidad federativa en México con mayor porcentaje de población que se auto reconoce como tal (con un 6.5\%), de acuerdo con la Encuesta Intercensal (2015). También, Guerrero es un estado que históricamente ha tenido alto grados de homicidios de mujeres y feminicidio, como da cuenta el Informe Feminicidio en México. Aproximación, tendencias y cambios, 1985-2016 (2017):

[...] ocupó el primer lugar en 2006 y 2007, el tercero en 2008 y 2009, el segundo lugar en 2011 y 2012, y en 2013 subió al primer lugar, donde se mantuvo en 2014 y 2015, para caer al segundo en 2016... De esta manera, se observa que el estado de Chihuahua, a pesar de haberse mantenido en el primer lugar nacional, ha presentado una importante reducción en el asesinato de mujeres en los últimos años, pasando de 32.4 en 2010 a 9.1 en 2014 y 6.8 en 2015, por cada 100,000 mujeres (SEGOB, INMUJERES, ONUMUJERES, 2017, p. 23-24).

Guerrero es una de las entidades más violentas de México contra las mujeres si se toma como indicador los homicidios de mujeres y el feminicidio. Sin embargo, llegar a esta afirmación y a la presentación de los datos en el citado informe no fue un proceso sencillo, implicó un proceso de disputa discursiva, para visibilizar el fenómeno.

Para alcanzar los objetivos planteados, estructuro el texto de la siguiente forma: En un primer apartado, muestro cómo fue le proceso de disputa por el reconocimiento del feminicidio en Guerrero y quiénes eran las y los actores; las estrategias discursivas en las dos partes del debate, la 
construcción de sentido $\mathrm{y}$, las etapas que siguió ese debate para construir el fenómeno.

En un segundo momento reflexiono sobre los informes oficiales de diversas instituciones del Estado, así como la sistematización de las organizaciones feministas, y el trabajo que se ha realizado desde la academia para mostrar la falta de consideración en la visibilización y análisis del feminicidio de un grupo racializado en específico: las mujeres afromexicanas.

En el tercer apartado presento un análisis de un feminicidio ocurrido en territorio afromexicano: Cuajinicuilapa ${ }^{5}$. Reflexiono sobre el problema que significa el acercamiento al análisis del feminicidio de mujeres afrodescendientes cuando no sabemos la auto adscripción de la víctima. Si bien, una deficiencia puede ser acercarse al fenómeno por el color de la piel y el fenotipo de las mujeres, ya que puede ser considerado biologicista. Sin embargo, asumo que este puede ser el primer paso para acercarnos a dimensionar el problema. Presento algunas líneas de hacia dónde seguir tanto los agentes del Estado, como las organizaciones feministas y la academia que se interese por el tema.

\footnotetext{
${ }^{5}$ Esto no quiere decir que el problema exista sólo en este municipio, por el contrario, el feminicidio existe en otros
}

\section{Contra la invisibilización. La lucha por el significado y por nombrar al feminicidio}

El territorio de Ciudad Juárez ha sido considerado el caso más notorio y paradigmático en torno a la violencia extrema contra las mujeres que culmina en el asesinato por razones de género (TAVERA, 2009; AIKIN, 2012; SEGATO 2012). Pese a que no fue, ni ha sido el único espacio donde se ha presentado este problema, si fue el que en un primer momento generó protesta social de activistas tanto en México como en otras partes del mundo, conformando lo que Aikin (2012) denomina como una "Red Transnacional de los Derechos de las Mujeres de Ciudad Juárez", con alcances y consecuencias que presionaron al gobierno mexicano para su actuación. El año 2002 es clave para la autora, porque ya estaba consolidada dicha red transnacional.

En el contexto de Guerrero y el proceso de denuncia de la violencia en contra de las mujeres en general y del feminicidio en particular, parto de las siguientes premisas: La primera es que los agentes del Estado en Guerrero han minimizado el feminicidio desde que éste fue puesto en la escena pública; y la segunda es que las mujeres organizadas feministas, activistas $y$

municipios de la Región Costa Chica (ALCOCER, 2017; 2019), 
académicas locales, interpelaron a los agentes del Estado y exigieron, mediante diversas estrategias, el reconocimiento del feminicidio en la entidad como un problema presente. Previo a la agenda en contra del feminicidio, existen, en el ámbito local Guerrerense demandas contra la violencia doméstica e intrafamiliar, sexual, y a favor de la defensa de los derechos de las mujeres.

Sobre los discursos construidos respecto al feminicidio y al proceso que se dio en la entidad, sostengo la existencia de dos grandes momentos: El primero en torno a la comparación de lo que sucede en Ciudad Juárez, que funciona como estrategia política por parte de las organizaciones de la sociedad civil; y por otro lado la negación de los agentes del Estado de parecerse a la ciudad fronteriza. El segundo momento lo delimito a partir de la identificación de que el feminicidio y los asesinatos de mujeres son minimizados por parte de los agentes del Estado al señalar que las víctimas son del crimen organizado.

\section{Primer momento: Ciudad Juárez, la referencia}

A partir de la prensa, desde 2003 se identifica que en Guerrero existen denuncias por parte de organizaciones de la sociedad civil en contra de los asesinatos de mujeres (esto no significa que previo a este año no se hicieran señalamientos sobre la violencia contra mujeres). Desde este año la prensa mostró diversos casos de asesinatos que conmocionaron a sus lectores como el de una empleada doméstica que fue "aserruchada" y "se le extrajo el feto" (PELÁEZ, 2003). A pesar de ese seguimiento que se le dio más allá de notas policíacas, aún no era frecuente llamar al fenómeno como feminicidio a nivel local.

Así, desde este año se identifica una disputa discursiva entre organizaciones de la sociedad civil y agentes del Estado, siendo Ciudad Juárez el referente narrativo. Demandas de integrantes de organizaciones de la sociedad civil, como el Movimiento por la Equidad de Género y en Defensa de los Derechos de las Mujeres A.C, en conjunto con actoras políticas, como la Diputada del Partido de la Revolución Democrática (PRD), Gloria Sierra López, señalaron la crueldad con la que estaban siendo asesinadas las mujeres en Acapulco de Juárez. Los títulos en la prensa que dan cuenta de esto son: "evocan a Ciudad Juárez y piden atender con puntualidad los asesinatos de mujeres en Acapulco" (PELÁEZ, 2003). Mientras que las respuestas los agentes del Estado se notaban en títulos como "Califica el fiscal especial de "aislados" los casos de mujeres asesinadas (NAVA, 2003).

Ciudad Juárez ha sido el referente para varias entidades. Por ejemplo, Villegas (2009), muestra que uno de los elementos 
para movilizar el discurso del feminicidio en Morelos fue la referencia a Ciudad Juárez. También, en Guerrero se identificó una estrategia parecida por parte de las organizaciones de la sociedad civil, que consistía en remitir lo que acontecía en Guerrero a esta ciudad fronteriza. A la par se comenzó a hacer recuento de los asesinatos para comenzar a visibilizar a las mujeres asesinadas: mencionaban sus nombres, cómo fueron encontradas, $\mathrm{o}$ asesinadas, $\mathrm{y}$ en general daban algunos elementos que permitían conocer el contexto o contextos de violencia, con títulos como "22 mujeres fueron asesinadas en Acapulco, según datos del SEMEFO”, (El Sur, 2004). La prensa y los artículos de opinión y de recuento fueron clave para las discusiones políticas, a diferencia de las notas de asesinatos, o nota roja, donde aparece "lo abyecto, lo desechado, lo que se puede sensacionalizar" (ALCOCER, 2014, p. 102)

Respecto a la primera estrategia para poner el tema en la agenda, tomando como referente lo que sucedía en Ciudad Juárez, el siguiente testimonio da cuenta de ello:

\footnotetext{
"Los casos recientes de asesinatos violentos de mujeres en Guerrero no deben ser vistos sólo desde un punto de vista policiaco y si tienen que atenderse con puntualidad, pues "por minimizar este tipo de crímenes en Ciudad Juárez (Chihuahua)" los casos aumentaron hasta convertirse en un problema de gobernabilidad en ese estado, afirmaron Rosa María
}

Gómez Saavedra, integrante del Movimiento por la Equidad de Género y en Defensa de los Derechos de las Mujeres, y la diputada loca (sic) Gloria Sierra López" (PELÁEZ, 2003: p. s/n).

La prensa local de Guerrero, desde 2003 pone el foco de atención en los "homicidios de mujeres" - aún no es denominado como feminicidio- y siempre se reportaban en comparación con el caso de Ciudad Juárez, como caso típico. Por ejemplo, señalaban que "Datos estadísticos indican que el año pasado Guerrero ocupó el octavo lugar de homicidios de mujeres, sólo tres lugares abajo de Chihuahua" (GUTIÉRREZ, 2003). Así, identifico que los asesinatos de mujeres en Guerrero están en la agenda pública, de la mano con la agenda fronteriza transnacional por los derechos de las mujeres en Ciudad Juárez.

Algunos reporteros y reporteras hacían lo propio para no dejar solo en la nota roja los asesinatos de mujeres, y comenzaron a hacer un conteo de cuántas víctimas eran, las casusas y el contexto en las que las encontraron, para ello tomaban como fuente de su información a las autoridades.

Este recuento y sistematización en la prensa se hace particularmente notorio en 2004 con notas periodísticas como el "Recuento final de mujeres asesinadas en Guerrero” (ZAMORA, 2004); o “¿Qué más tenemos que ver?" (GARCÍA, 2004). Otro 
ejemplo que da cuenta del hecho de que las autoridades comenzaban a responder a las demandas de grupos organizados: "Darán a conocer información sobre crímenes contra mujeres" (TORRES, 2004).

Un ejemplo de la descripción del contexto en la entidad es el reporte que hizo la periodista Elsa Zamora:

En el mes de noviembre asesinaron a Leonilda [...] a quien mataron a golpes y trataron de abrir su vientre de seis meses de embarazo.

El 27 de noviembre, María José de la Rosa Vargas la asesinó a golpes su esposo Juan Antonio Moreno Garduño, en la (sic) su casa; [...] Otro caso que dejó a la comunidad guerrerense estupefacta el 5 de noviembre fue el de la mujer trabajadora del tutelar de menores Estela García Santos, quien fue asesinada por uno de los internos de ese lugar con verdadera saña.

En octubre se supo de una mujer de nombre María Elena González que asesinaron, pusieron en una maleta y dejaron en un autobús de pasajeros... (ZAMORA, 2004, p. s/n).

Sin embargo, ya para el año 2005, en Guerrero se tenía delineado el fenómeno del feminicidio como un problema presente y se exigía el reconocimiento en la entidad. Títulos de notas como "Feminicidios, inequidad e injusticia” (OJEDA, 2005), daban cuenta de ello.

\footnotetext{
${ }^{6}$ El Equipo de Investigación fue coordinado por la Dra. Rosa Icela Ojeda Rivera; las investigadoras fueron la Lic. Bernardina Zazocoteco Sanjuán, Walfred Geovanni Manrique Pastor, Marisol Alcocer Perulero, Karina
}

Es en este contexto que el feminicidio no era reconocido como un problema en la entidad por parte de las instituciones del estado, por lo que se planteó como urgente la necesidad documentar el fenómeno en Guerrero por parte de activistas y observatorios de violencia. Una institución académica que fue fundamental para la visibilización es el Observatorio de Violencia Contra las Mujeres de Guerrero "Hannah Arendt", creado en 2005 y fundado por la Investigadora Rosa Icela Ojeda Rivera. Fue el observatorio quien estuvo a cargo de la realización de la investigación que dio como resultado el Informe Violencia feminicida en Guerrero, (2006) ${ }^{6}$. Por ello, para 2005, año en que inició la investigación, ya el feminicidio estaba siendo parte de la agenda política y pública en la entidad.

¿Cuál fue la respuesta del Estado? Si bien los asesinatos de mujeres por razones de género estaban presentes más allá de Ciudad Juárez, no era un discurso compartido. El discurso oficial iba en el sentido de que los asesinatos denunciados por las organizaciones civiles eran casos "aislados", así lo declaró el fiscal de la Procuraduría de Justicia en Guerrero, Fernando Monreal Leyva. Una nota periodística en 2003 describía que:

Estefanía Hernández Ojeda, Aline Mara Eguia-Liz, Líbana Nacif Heredia y Guadalupe Karina Blanco Cuevas. 
[...] Los casos que se han divulgado más son los de la directora de la Preparatoria 14 de la Universidad Autónoma de Guerrero (UAG), Lourdes Chavelas Cruz; Amada Hernández López de 35 años, quien semidesnuda fue encontrada en el interior de un camión abandonado [...] y el de la doméstica Leonila Gallardo Román, de 22 años, quien contaba con seis meses de embarazo $\mathrm{y}$ fue brutalmente asesinada.

Según Monreal Leyva en cada uno de ellos hay características diversas y no se puede establecer que todos tengan una relación" (NAVA, 2003, p. s/n).

Los contextos en los cuales se presentaban los asesinatos eran distintos, sin embargo, lo que los relaciona entre sí es que son mujeres asesinadas en el marco de relaciones asimétricas de poder intergenéricas, donde el desprecio por la vida de las mujeres era el común denominador, aunque cada una de ellas insertas en sus propios contextos de precariedad.

Dos años después el Subprocurador de Procedimientos Penales de la Procuraduría General de Justicia del Estado (PGJE), Antonio Nogueda Carvajal, también minimizó los asesinatos de mujeres y el feminicidio en Guerrero al señalar que:

[...] los casos de violencia contra las mujeres en Guerrero han sido investigados incluso por la Procuraduría General de la República y que los resultados son en el sentido de que "no existe ninguna relación o similitud con lo que pasa en Ciudad Juárez" (CERVANTES, 2005, p. s/n).

La búsqueda por diferenciarse de la "Ciudad estigmatizada" por "las muertas" de la ciudad fronteriza lleva a un discurso específico por parte de los agentes del Estado. Las demandas de las organizaciones de la sociedad civil no era solo que llegaríamos a tener los grados de Ciudad Juárez, demandaban el reconocimiento del problema de los asesinatos en el marco de relaciones desiguales de género en la entidad : que había mujeres asesinadas por el hecho de ser mujeres a manos de sus parejas, o no, abusadas sexualmente, y que se resumía en la consideración de ellas como mercancía, lo que Martin y Wilson (2006) denominan considerar a la mujer como propiedad sexual de un hombre.

Ese contexto de violencia de género se identifica en el siguiente testimonio, en voz del agente del estado:

"Nogueda Carvajal [...] negó que los asesinatos de las dos estudiantes de la preparatoria 5 de la UAG en Ometepec, así como de las dos maestras secuestradas [...] se trate de un asunto de misoginia o una situación parecida a los casos de las muertas de Ciudad Juárez, Chihuahua

Explicó que, en el caso de Candelaria, existen evidencias de que antes de ser asesinada a navajazos fue violada por sus victimarios y que una de las líneas de investigación que se están siguiendo es la mala relación que 
tenía con algunos vecinos (NAVA, 2005, p. s/n).

La violación es una expresión de misoginia que se conjunta con el colonialismo, en ese sentido solo basta recordar que "el dominio imperial y colonial consideraba la violación de una mujer esclava negra como el privilegio de su propietario" (RADFORD, 2006, p. 43). Candelaria, una joven estudiante indígena fue encontrada asesinada en un lote, sufrió violación sexual y fue estrangulada (LORENZO, 2005). Todos los elementos que constituyen el paradigma feminista de feminicidio, (aunque en esa fecha aún no estaba tipificado legalmente en la entidad, la cual se logró hasta 2010).

Las respuestas de los agentes del Estado iban en dos sentidos: o negaban el fenómeno; o bien eran contradictorias. Por ejemplo, por un lado, el título de la nota siguiente señala que "Reconocen autoridades que en Guerrero existe alto índice de asesinatos de mujeres" (AGUSTÍN, 2005), pero en el cuerpo del texto dicen:

En realidad hay un porcentaje muy bajo de asesinatos en contra de mujeres, pero como ya van muchos homicidios, por bajo que sea, hay un número considerable de mujeres que son muertas violentamente", anotó el procurador general de Justicia, Eduardo Murrueta Urrutia.

\footnotetext{
${ }^{7}$ Por otro lado, de acuerdo con El informe: Feminicidio en México. Aproximación, tendencias y cambios, 19852016, (2016), en 2005 Guerrero estaba en el cuarto lugar
}

[...] comentó que recientemente estuvo buscando en Internet y los C4 de otros estados para ver si podía encontrar información alusiva al caso y no pudo, por lo que se espera que en la próxima conferencia nacional de procuradores de Justicia pueda recibir los datos que necesita, para saber con claridad en qué lugar se encuentra Guerrero en lo que se refiere a feminicidios (AGUSTÍN, 2005, p. s/n [cursivas mías]).

A pesar de la ambigüedad y las contradicciones, este testimonio es importante porque pocas veces las instituciones de procuración de justicia nombraban al fenómeno como feminicidio ${ }^{7}$.

\section{Segundo momento discursivo del feminicidio: "son del crimen organizado"}

Las autoridades tienden a atribuir las muertes violentas al crimen organizado (MELGAR, 2011; CATÓLICAS POR EL DERECHO A DECIDIR, 2012). Guerrero no es la excepción. De ello dan cuentan algunas declaraciones como la de la Titular de la Procuraduría General de Justicia de Guerrero, Martha Elva Garzón Bernal, quien rechazó "que en el estado haya un repunte en los casos de feminicidios, ya que, de acuerdo con su registro, la mayor parte de las mujeres asesinadas durante 2011 y 2012 estaban

respecto a la Tasa de defunciones femeninas con presunción de homicidio y pasó al primer lugar en 2006. 
relacionadas con el crimen organizado"

(AGUSTÍN, 2012, p. s/n).

Respecto a las cifras, la Fiscal Especializada para la Investigación de Homicidio Doloso en Agravio de Mujeres y Demás Personas con Orientación o Preferencia Sexual por Identidad de Género, de la entonces Procuraduría General de Justicia del Estado $(\mathrm{PGJE})^{8}$, María Guadalupe Rendón Ramírez, señaló en la prensa que "sólo tres feminicidios se han registrado en Guerrero en lo que va del año" (CRUZ, 2011), (refiriéndose al año 2011).

Ante este contexto, si una víctima estuvo dentro del crimen organizado ¿es merecedora de una investigación para aclarar el asesinato? Difícilmente puede haber investigación cuando asesinan a mujeres “del crimen", si desde un principio no es considerada como víctima de algún delito, y ha sido clasificada en cierto grupo carente de “inteligibilidad” (BUTLER, 2009). No tiene el mismo impacto, tal como lo relata en una entrevista una agente del estado encargada de procuración de justicia:

[...] si yo decido pertenecer a un grupo delictivo, yo llevo una aceptación de las consecuencias que esto puede pasar, y que ahí existe una laguna en la ley porque, si bien es cierto es una mujer que se priva de la vida, pero también es un acto

\footnotetext{
${ }^{8}$ La ley Orgánica De La Fiscalía General Del Estado De Guerrero. Número 500, publicada en 2016, al entrar en
}

que yo estoy consintiendo al pertenecer a ese grupo delictivo, y las consecuencias ahí ya no son las mismas que pudieran ser en el homicidio de una ama de casa [...] porque una ama de casa puede estar en su domicilio, realizando sus labores, o estando descansando, puede llegar ahí una persona y la puede privar de la vida, a diferencia de lo que es una mujer que anda robando, que anda privando de la libertad, o sea no es la misma situación son cuestiones completamente distintas (ENTREVISTA A AGENTE DEL ESTADO 1, Chilpancingo, 10 de enero de 2011).

Las mujeres señaladas como parte del crimen organizado, nos lleva a lo que Butler teoriza sobre las vidas precarias cuando señala que:

[...]muchas poblaciones que se encuentran en el margen no son conceptualizadas como inteligibles, $\mathrm{y}$ alguna de ellas es vista como una amenaza a la inteligibilidad misma: irracionales, violentas, monstruosas, etc. Por tanto, se trata de un a priori histórico, pero un a priori sujeto a transformaciones (BUTLER, 2009, p. 71)

En esta segunda etapa por el reconocimiento del feminicidio y de los homicidios de mujeres en el marco de una violencia generalizada de la "guerra contra el narcotráfico", las organizaciones feministas también han interpelado al estado. Por

vigor derogó la Ley Orgánica de la Procuraduría General de Justicia del Estado de Guerrero. 
ejemplo, las solicitantes de la Alerta de Violencia de Género en Guerrero ${ }^{9}$ señalaron

[...] que la violencia contra las mujeres en Guerrero es invisibilizada y minimizada por el gobierno, incluso en ocasiones, las muertes de mujeres se justifican cuando están relacionadas con el crimen organizado, o bien, se reducen a crímenes pasionales" (CONAVIM, 2016, p. 19).

El campo de disputa por el significado se da, entre nombrar al feminicidio y el no reconocerlo; entre organizaciones feministas y los agentes del Estado. Cada uno con sus propias estrategias, donde se tiene que considerar que,

Los terrenos discursivos se traslapan, se influyen y compiten entre sí; hacen llamados a sus respectivas "verdades" en busca de autoridad y legitimación. Se piensa que esas verdades están fuera de la invención humana, que son conocidas o evidentes, o que pueden ser descubiertas mediante la investigación científica. Precisamente porque se les asigna el estatus de conocimiento objetivo, parecen estar más allá del cuestionamiento y por lo tanto tienen una poderosa función legitimadora" (SCOTT, 1992, p. 88).

El discurso del feminicidio también terminó por buscar autoridad con base en los

\footnotetext{
${ }^{9}$ En el artículo 22 de la Ley General de Acceso de las Mujeres a una Vida Libre de Violencia, se menciona que la alerta de violencia de género "es el conjunto de acciones gubernamentales de emergencia para enfrentar y erradicar la violencia feminicida en un territorio determinado, ya sea ejercida por individuos o por la propia comunidad." En Guerrero se solicitó en 2016, la
}

datos duros científicos. En este mismo sentido, Figueroa (2019) argumenta que la estadística y los datos respecto a la violencia contra las mujeres “ $[. .$.$] construye verdad y da cuenta de$ la gravedad del fenómeno por la recurrencia de los indicadores y su aumento en el tiempo" ( $p$. 70). Es ahí donde las organizaciones de la sociedad civil le disputaron "su verdad" a los agentes del Estado.

La tensión entre el "existe el feminicidio" y el "aquí no pasa lo que en Ciudad Juárez', entre lo que es construido como "verdad" y lo "que es "aislado" va configurando dos extremos que siguen disputando. La voz oficial institucional y legítima, la voz del experto, -los agentes del Estado-, y del grupo que disputa -feministas organizadas, que también son voces expertas en la sistematización del fenómeno.

\section{Las afrodescendientes dentro de lo étnico y el significado del feminicidio}

En la disputa por la construcción del significado del feminicidio, las víctimas afromexicanas siguen sin ser visibilizadas tanto en los datos e informes oficiales, como en

Alerta para ocho municipios: Acapulco de Juárez, Ayutla de los Libres, Chilpancingo de los Bravo, Coyuca. La organización peticionaria fue la Asociación Guerrerense contra la Violencia hacia las Mujeres, A.C., de catalán, Iguala de la Independencia, José Azueta, Ometepec y Tlapa de Comonfort, 
los datos que sistematizan las organizaciones de la sociedad civil, y en la prensa.

Pocas veces el fenómeno ha sido reflexionado considerando elementos que concatenan las condiciones de opresión de las mujeres más allá del género, lo que trae como resultado la exclusión de las experiencias de las mujeres racializadas.

Esto a pesar de que existen demandas por parte de organizaciones de mujeres. De eso da cuenta la Declaratoria Mujeres Afromexicanas de la Costa Chica $^{10}$ que a la letra dice:

Las mujeres afromexicanas vivimos múltiples formas de violencias que han llegado al feminicidio donde podemos decir que pocos casos llegan a la justicia, resalta de manera especial la violencia sexual de la cual somos víctimas por el estereotipo que existe de ser sexualmente disponibles (ILSB, s/f)

Las mujeres racializadas en México, indígenas, y afromexicanas, mestizas - han sido excluidas de la disputa discursiva y la sistematización de información cuantitativa o cualitativa en el problema del feminicidio.

Lo anterior no anula que haya habido cierta discusión y mediatización de algunos casos de feminicidio de mujeres indígenas, tal como como da cuenta el siguiente testimonio:
Una alumna esmerada, responsable, alegre y con una idea en mente de emigrar a Estados Unidos para mejorar su nivel de vida, son las características que definen a Daniela Martínez, mujer indígena de 18 años... originaria del municipio de Quechultenango y radicada en esta capital desde hace varios años, por las mañanas realizaba labores domésticas en la casa de la dueña del restaurante Mastaches $\mathrm{y}$ Tacostumbras de esta capital y por la tarde estudiaba en la preparatoria 33 de la UAG donde cursaba el tercer grado y los fines de semana trabajaba en una papelería[...] (FLORES, 2006, p. s/n [cursivas son mías]).

Ser indígena o ser asesinada en algún territorio, sea con alta presencia de población indígena, o no, siempre es señalado en la prensa. Títulos como "Porque le fue infiel, un indígena asesinó a su esposa en Tlapa frente a sus tres hijos" (GONZÁLEZ, 2007, p. s/n). Se observa que conjuntan elementos de género, por ejemplo, la infidelidad como causa del asesinato, pero el encabezado enfatiza la parte étnica como marca que constantemente es noticiable (el indígena como asesino). Sin embargo, esto no es discutir la etnia ni los impactos del racismo sobre la población indígena, y más aún, sigue estando ausente lo afrodescendiente.

En las notas periodísticas locales, revisadas desde 2003 al 2017, nunca se 
menciona que una mujer mestiza, o afromexicana, negra o morena haya sido asesinada, a pesar de las múltiples narrativas que destacan el fenotipo de algunas víctimas: "Morena, de cabello chino, de buen cuerpo" (AÑORVE, 2013, p. s/f), que dan pistas de los homicidios y el feminicidio de mujeres racializadas. Pero ¿es suficiente con que la prensa mencione que la mujer asesinada es morena? Aquí radica uno de los grandes retos que tiene que ver con el uso de la categoría afromexicana, misma que es resultado de un sentido y reivindicación política, lo cual no todas las mujeres radicadas en territorios con población afrodescendiente, negra o morena reconocen.

Así, el vacío de conocimiento respecto a la información desagregada por grupo étnico en México y en Guerrero, se agrega la falta de datos confiables, como obstáculos para entender cómo es la situación de violencia extrema que viven las mujeres en el país.

La visibilización cualitativa del feminicidio y homicidios de mujeres en municipios considerados afromexicanos y a nivel comunitario en Guerrero es reciente. En otra investigación (ALCOCER, 2017), muestro que al interior de dos comunidades afromexicanas -San Nicolás y El Pitahayo, del municipio de Cuajinicuilapa, las víctimas de feminicidio eran mujeres que no tenían lazos comunitarios, entre otras cosas, porque eran originarias de otras comunidades y municipios, y además tenían trabajos socialmente estigmatizado, como mesera de una cantina, trabajadora sexual en contextos de pobreza.

¿Por qué es importante conocer la etnicidad y las particularidades de las mujeres afromexicanas en Guerrero y en México? Al no abordarse la racialización en el feminicidio -y no generar información-, no se están recuperando ciertas especificidades que hacen que se enmarque una diferencia en las relaciones de poder, lo que lleva a la concatenación con otras violencias estructurales. El feminicidio y homicidio de mujeres afromexicanas, negras o morenas asesinadas dentro de sus comunidades o fuera de ellas, tanto por conocidos, o desconocidos, requiere de un análisis " [...] para exponer la dimensión racista y machista de los mismos" (RADFORD, 2006, p. 292). Al ser grupos históricamente discriminados, el elemento étnico-racial debe ser información mínima que debe ser registrada según el Protocolo De Bogotá, sobre Calidad de los Datos de Homicidio en América Latina y el Caribe.

Las mujeres afromexicanas son y han sido racializadas históricamente, lo que trae como resultado que sobre sus cuerpos se construyan percepciones, representaciones, valorizaciones e ideas, no sólo a partir de una "diferencia sexual", sino de su diferencia étnica y fenotípica. Si no consideramos la racialización, no podremos entender la 
complejidad del fenómeno. Comparto la idea de Stuart Hall respecto a que la dimensión biológica está presente en la discriminación contra los pueblos negros o afrodescendientes (HALL, 2010), ya que la "raza" y el racismo:

"[...] ha operado como un signo de que las personas de ascendencia africana están más cercanas a la naturaleza y, por lo tanto, tienen más probabilidades de ser flojos, indolentes, carecer de elevadas facultades intelectuales, dejarse llevar por la emoción y el sentimiento antes que por la razón, ser híper sexuales, tener poco autocontrol y ser proclives a la violencia, etc. (p. 597).

No hay "mujer universal" (HARDING, 2002), y aquí las mujeres afrodescendientes han cuestionado la categoría "mujer" por su pretensión universal (CURIEL, 2007). Tal cuestionamiento permite señalar que las violencias no las afecta igual por el hecho de ser mujeres, porque el trato pasa por el racismo y la percepción que se tiene de las personas a partir de su apariencia, color de piel, por ejemplo. Esto lo evidencian las mujeres activistas negras, quienes denuncian que:

"El personal de salud brinda una atención racista, porque no nos atienden de manera inmediata cuando estamos en labor de parto, porque tienen la idea de que las "mujeres negras aguantan más" lo cual ha generado muertes maternas e infantiles que no son visibles" (ILSB, 2016, p. s/n).
La apuesta política y analítica en este texto es cuestionar el hecho de que la violencia extrema que culmina en el asesinato de las mujeres afecta de la misma forma y en las mismas circunstancias, por ser mujeres. Desuniversalizar la idea de que en el feminicidio solo existe el marcador de género es un reto académico y político, porque en el ejercicio de las violencias existen otros marcadores sociales que pasan por el cuerpo, las subjetividades y experiencias de las mujeres. La reflexión y sistematización del feminicidio debe considerar que lo masculino y lo femenino son siempre categorías que se producen y aplican dentro de una clase, en relaciones sociales racializadas y una cultura particular. Obviar estos elementos reproduce la visión hegemónica, ya que no acepta las experiencias y voces diversas.

En el caso de las mujeres negras, morenas o afrodescendientes de Guerrero y México, la característica ha sido la opacidad social histórica de la identidad afromexicana y la condición étnico-racial y su relación con la desigualdad social, en el marco de un racismo institucional, esto ha traído como resultado la falta de visibilización y registro del feminicidio y homicidio. En este sentido, el Censo de Población y Vivienda de 2020 significó una oportunidad para resarcir mínimamente la deuda que se tienen con la población. Por vez primera se preguntó a la población si “Por sus antepasados y de acuerdo a sus costumbres y 
tradiciones ¿se considera afromexicano/a, negro/a o afrodescendiente?" (SENADO, 2020), activistas y académicas como Mónica Moreno, apuntan que:

El censo nos abre la posibilidad de tener esta discusión y de entender mejor cómo funciona la desigualdad [...] Sabemos que la población afrodescendiente e indígena se concentra históricamente en las zonas más castigadas por la pobreza y la exclusión, pero no sabemos cuánto se debe a discriminación y cuánto a las características de esas regiones" (EL PAÍS, 2020, [cursivas son mías])

\section{La ausencia de la condición étnico-racial en los datos de feminicidio}

El Censo de Población y Vivienda 2020 es el primer momento y, significa una oportunidad para reconocer y ubicar el feminicidio considerando lo étnico y racial. Con ello, los agentes del Estado encargados de procurar e impartir justicia tendrán más herramientas en primera para generar registros de homicidios y feminicidio, porque mínimamente ya tendrán información sobre los territorios donde está la población, cómo son asesinadas las mujeres, en intersección de otros elementos sociales. Son ellos quienes tienen la obligación de generarla, en primer lugar.

\footnotetext{
11 Véase la consulta, disponible en http://bdsocial.inmujeres.gob.mx/index.php/ensademi-
}

Si bien, ha habido algunos intentos por reconocer lo étnico-racial para comprender la situación de violencia, como la Encuesta de Salud y Derechos de las Mujeres Indígenas (ENSADEMI, 2008) ${ }^{11}$, ésta tampoco contemplaba a la población afromexicana y no ha habido continuidad.

Recapitulo que, para las instituciones encargadas y obligadas de generar información confiable en Guerrero, la problemática y experiencia de las mujeres afromexicanas o negras, víctimas de feminicidio no ha sido central. Por ejemplo, en la Investigación sobre Violencia feminicida en 10 entidades de la República, que inició en 2005 y se publicó en 2006, seleccionaron algunas entidades para hacer análisis comparativo sobre los homicidios de mujeres en México. Las 10 entidades fueron: Estado de México, Veracruz, Chiapas, Guerrero, Distrito Federal (hoy Ciudad de México), Chihuahua, Oaxaca, Sonora, Baja California y Morelos. En este sentido, Guerrero, Oaxaca, Veracruz y Chiapas fueron seleccionados por ser "entidades pluriétnicas". No obstante, para el caso concreto de Guerrero, el informe "Violencia feminicida en Guerrero" solo menciona los cuatro pueblos indígenas, sin hacer referencias a la situación de la población negra o afrodescendiente.

286/encuesta-de-salud-y-derechos-de-las-mujeresindigenas última consulta 03 de junio de 2020. 
En 2011 se publicó el informe Feminicidio en México. Aproximación, tendencias y cambios, 1985-2009, estudio que por primera vez presenta información para las 32 entidades del país y hace una sistematización de los registros de defunciones femeninas con presunción de homicidio en un periodo extenso, iniciando en 1985 al 2009, y después se fue actualizando la información que abarcaba 1985 a 2016. Esta investigación muestra las características de los asesinatos de mujeres y visibiliza la situación y los distintos contextos en los que se presenta. No obstante, deja fuera elementos fundamentales como si los municipios donde se presenta el homicidio de mujeres son indígenas, o el elemento étnico-racial de las víctimas. Las mujeres y comunidades afromexicanas, ni si quiera son pensadas.

A nivel local, en 2016 en el marco del proceso de Solicitud de la Declaratoria de la Alerta de Género ${ }^{12}$, el informe realizado por el Grupo de Trabajo para atender la solicitud de AVG en Guerrero presentó el panorama de la situación de violencia contra mujeres, donde los datos oficiales proporcionadas por las autoridades del estado eran la fuente de información. Señalan que para el periodo 2009 a 2016 fueron registrados 743 homicidios dolosos y 53 feminicidios. Refiere

\footnotetext{
${ }^{12}$ Para un análisis del proceso de la Alerta véase la tesis de Maestría en Políticas Públicas y Género de Rosas, Itzel (2018) "Evaluación del diseño de la Alerta de Violencia de Género como política de emergencia ante los
}

que a pesar de que casi en todos los casos se identificó a las víctimas

“[...] no se logró precisar en casi ninguno si pertenecían a alguna comunidad indígena, en la mayoría no se ha identificado al victimario, ni lograron precisar si la víctima era beneficiaria de alguna medida de protección o si existía denuncia previa" (CONAVIM, 2016, p. 67 [las cursivas son mías]).

El grupo no hace comentario alguno sobre la falta de datos de homicidios $y$ feminicidio sobre las comunidades afrodescendientes que existen en Guerrero, y si la víctima era o no afrodescendiente, negra o afromexicana. A pesar de ello, en sus recomendaciones sí mencionan que las campañas y las acciones deben contemplar a las mujeres indígenas y afromexicanas.

Por otro lado, desde la sociedad civil, las peticionarias de la Alerta de Género en 2016 presentaron el Diagnóstico Sobre el estado que guarda la violencia feminicida en Guerrero, en el que, si bien sólo presentan algunos relatos, estos dan elementos para entender los contextos de violencias estructurales - generalizadas en la entidad.

En la información refieren a algunos casos de mujeres indígenas que fueron asesinadas, como el de "la joven indígena que es seducida por un hombre casado y mayor

feminicidios: el caso del estado de Guerrero" FLACSO, México. 
para hacer negocio con el alquiler de su maternidad y al negarse a cumplir el trato fue liquidada e incinerada" (ALIANZA DE MUJERES FEMINISTAS, 2016, p. 25); O en 2007, cuando "Una mujer de rasgos indígenas se reportó en calidad de desconocida, fue encontrada por sus vecinos dentro de su domicilio, en avanzado estado de descomposición," (Ibid p. 31[las cursivas son mías]). Un caso emblemático que mencionan es el feminicidio de Manuela García de la Cruz, indígena amuzga asesinada, en 2008, por su compañero sentimental, Arturo Marciano de Jesús, Delegado de Asuntos indígenas del gobierno del estado.

Sin duda, el trabajo que hacen las organizaciones civiles es mucho más detallado en términos del contexto, porque sí especifican las características del feminicidio de mujeres indígenas. Pero, sigue sin haber evidencia de mujeres afromexicanas.

Esta situación se explica, en gran medida, porque tanto el trabajo de académicas y organizaciones de la sociedad civil en Guerrero se basa en información de la prensa, $\mathrm{y}$ en ésta las afrodescendientes no son nombradas, ni en los artículos de opinión, ni en la nota roja. Por lo tanto, la prensa si considera de interés si la víctima es indígena, o si el agresor lo es, (los títulos dan cuenta de ello), mientras que la afrodescendencia no se considera.

\section{¿Hacia dónde ir? Nuevas formas de trabajo colaborativo en campo}

En la forma en cómo está recabada la información sobre el feminicidio y homicidios de mujeres es imposible distinguir a las mujeres afromexicanas, negras $\mathrm{o}$ morenas ni en Guerrero, ni en México. Las grandes interrogantes que surgen giran en torno a cuáles son los elementos para considerar a las víctimas de feminicidio y homicidio como afromexicana, negra o morena. Acaso ¿la autoidentificación?, ¿los rasgos físicos?, o ¿ambas? ¿qué hacer cuando no se registra la identidad indígena $o$ afromexicana en los datos que construyen desde las instituciones del Estado? De entrada, tenemos que cuestionarnos las formas en cómo se ha sistematizado la información. En primer lugar, cuestionar el papel de las instituciones del Estado en la recopilación de registros administrativos y procuración e impartición de justicia; después a las metodologías de sistematización de las organizaciones de la sociedad civil de mujeres organizadas.

Las instituciones y los agentes del Estado no han cumplido con la población afrodescendiente, entre otras cosas, en cuestión de procuración de justicia en el caso de homicidios y feminicidio. Esto a pesar de que en 2014 se estableció que Guerrero sustenta su identidad multiétnica, 
plurilingüística y pluricultural también en sus comunidades afromexicanas (Art. 8, CONSTITUCIÓN POLÍTICA DEL ESTADO LIBRE Y SOBERANO DE GUERRERO). Desde entonces, a pesar del reconocimiento en la constitución local, las comunidades afromexicanas no han sido tomadas en cuenta en la generación de información en materia de procuración de justicia.

¿Qué le compete realizar a las instituciones encargadas de la procuración de justicia?

En primer lugar, un trabajo de apertura y acercamiento con las mujeres negras, afromexicanas organizadas. De entrada, la Fiscalía General del Estado de Guerrero es la institución que debería tener mayor sensibilidad en el tema porque son quiénes generan los datos. Por ejemplo, al solicitar información a la Comisión Nacional para Prevenir y Erradicar la Violencia Contra las Mujeres (CONAVIM) ${ }^{13}$, para intentar tener un panorama del feminicidio $\mathrm{y}$ homicidio de mujeres en Guerrero a un nivel local, proporcionaron los siguientes elementos: Averiguación previa; número de carpeta o de investigación; delito (homicidio y feminicidio), modalidad, y tipo de arma con la que se cometió; fecha de inicio; lugar de los

\footnotetext{
${ }^{13}$ Solicité la información a CONAVIM, vía transparencia, folio número 0400200005416. Esta institución federal, me brindó la información que previamente fue facilitada por la Fiscalía General del Estado de Guerrero.
}

hechos; posible móvil; si existía denuncia previa a la muerte por algún tipo de violencia o lesiones; y e si la víctima tenía alguna orden de protección previa y en que consistieron las medidas implementadas. Estos indicadores dan pie para identificar en un primer momento los municipios y localidades en donde se presentan los homicidios y el feminicidio; y 2, el tipo o tipología de feminicidio -si fue cometido por parejas, exparejas o con quien haya habido una relación afectiva.

En otro ejercicio de solicitud de información, requerí los datos directamente a la Fiscalía General Del Estado ${ }^{14}$. Esta instancia brindó los datos de manera más completa para el periodo de 2011 (año en que comienzan a registrar el delito de feminicidio en la institución, porque ya estaba tipificado como delito) a 2017. Entre las características reportadas se encuentran: el estrato social, nacionalidad, si tenía condición de inmigrante; ocupación; si pertenecía a un grupo étnico. Sin embargo, no informaron que hubiera víctimas de feminicidio indígenas, mucho menos afromexicanas, negras o morenas en Guerrero. Esta es una de las grandes deficiencias.

$\mathrm{Si}$ consideramos que una de las obligaciones de los agentes del Estado en

\footnotetext{
${ }^{14}$ La respuesta de se hizo legar mediante oficio con número FGE/CI/UTAI/0051/2018, con fecha del 22 de enero de 2018
} 
Guerrero es aplicar el Protocolo de Investigación Ministerial, Policial y pericial con Perspectiva de Género para el Delito de Feminicidio (GOBIERNO DEL ESTADO DE GUERRERO, 2017), este se deberá ver reflejado en la recolección de datos para especificar, entre otros elementos, la "pertenencia o no a algún grupo indígena" de las víctimas, establecido en el artículo 33, sección XI de dicho documento. A lo ya establecido, es fundamental que se agregue la pertenencia o no al pueblo afromexicano. Específicamente se debe poner atención al apartado sobre los Lineamientos en casos de niñas y mujeres en situación especial de vulnerabilidad (Capítulo IV, artículos 36 y 37), e incluir a las mujeres y niñas afromexicanas o negras.

En este sentido, la función de la Fiscalía Especializada para la Investigación del Delito de Homicidio Doloso Cometido en Agravio de Mujeres y demás Personas con Orientación o Preferencia Sexual por Identidad o Expresión de Género, es fundamental. Se debe establecer en el artículo 67, del Reglamento De La Ley Orgánica De La Fiscalía General Del Estado De Guerrero Número 500, que se encargue de la recopilación de información sobre el grupo étnico al que pertenecen las mujeres asesinadas, sean indígenas, afromexicanas, negras o morenas. Incluir otros elementos que ya se han establecido en el Informe de
Solicitud de Alerta de Género (CONAVIM, 2016) y en el Protocolo de Feminicidio (2017), tales como la situación migratoria interna o de desplazamiento forzado de la víctima, la posibilidad de que existieran antecedentes de alguna denuncia previa por violencia u orden de protección. Además, elementos respecto a la violencia sexual, donde fue encontrada la víctima y donde fue asesinada. Esta información permitirá comprender la situación de los contextos de las víctimas de feminicidio en Guerrero.

Con esto se hará efectivo el protocolo de Bogotá sobre calidad de los datos de homicidio en América Latina y el Caribe, especialmente la variable que indica que se debe recolectar información sobre "Características adicionales relativas a grupos de riesgo, en función del contexto local, tales como raza y/o grupo étnico, orientación sexual, identidad de género, nivel socioeconómico" (CÁMARA DE COMERCIO DE BOGOTÁ, ET AL, 2016, p. 7).

Sin embargo, a las deficiencias en la normatividad por no registrar a el grupo étnico afromexicano en el protocolo de feminicidio, se agregan las debidas al registro. Es decir, puede suceder que, aunque esté establecido en la norma, probablemente no sea registrado, tal y como se evidencia en el caso de mujeres indígenas y la poca información brindada al respecto. 
Es evidente que las fuentes de información estadísticas tienen limitaciones. Los registros oficiales como los del Instituto Nacional de Estadística y Geografía INEGI carecen de la minuciosidad del contexto, tales como si hubo violencia sexual, si es indígena o afromexicana, etc.; cuando se toma la fuente de las Fiscalías los asesinatos no siempre llegan al ministerio público, o familiares no permiten el levantamiento, por lo que no siempre existe apertura de una averiguación previa. Así la información que brindan pueden no ser el total de asesinatos ocurridos. Por otro lado, la prensa, que es el referente de organizaciones de la sociedad civil y observatorios, no siempre llega a cubrir el asesinato, además que la información que brinda puede ser imprecisa (por ejemplo, que cambien los nombres, la edad de las víctimas, etc.).

Entonces ¿qué hacer junto con las mujeres organizadas que sistematizan los homicidios y el feminicidio en Guerrero? Un aspecto pendiente es todavía al trabajo de campo en las comunidades con mujeres afrodescendientes, negras, o morenas organizadas; a la par realizar trabajo con las mujeres que no están organizadas, o que no se reconocen afromexicanas y/o feministas, para también entender el sentido que le dan a la violencia y las formas en cómo están enfrentándola.
Es fundamental descolonizar el pensamiento y el activismo para que las voces de las mujeres diversas sean escuchadas. En ese sentido, por ejemplo, un cuestionamiento que se le ha hecho a las feministas peticionarias de la Alerta de Género por parte de mujeres afromexicanas organizadas ha sido justo la falta de inclusión en el proceso de solicitud. Patricia Ramírez, mujer afromexicana destaca:

Fuimos llamadas en un inicio, pero después no se tomó en cuenta. Según las estadísticas, en la Costa Chica no hay feminicidios, ni violencia sexual. ¿Por qué nos van a incluir en la alerta de género si no hay negras ni feminicidios negros? Es un tema muy amplio del cual hemos sido excluidas" (CLARÍN, 2016, p. s/n).

Si bien, ha habido acercamientos e informes sobre la existencia de feminicidio y homicidio en la Región de la Costa Chica que dan cuenta del panorama, es real que no se conoce el feminicidio de mujeres afromexicanas a nivel estatal, ni nacional. En términos amplios hay un vacío, y esta es una demanda de las mujeres afromexicanas de la Costa Chica, esto debido a que:

No hay estadísticas que permitan conocer la situación y condiciones de vida concretas de las mujeres Afromexicanas, desde nuestra experiencia de vida, compartimos:

Las mujeres afromexicanas vivimos múltiples formas de violencias que han llegado al feminicidio donde 
podemos decir que pocos casos llegan a la justicia, resalta de manera especial la violencia sexual de la cual somos víctimas por el estereotipo que existe de ser sexualmente disponibles." (ILSB, 2016, [cursivas son mías]).

Uno de los retos es pensar en los puentes entre el activismo feminista, y el activismo -se denominen feminista o no- de mujeres afromexicanas que han trabajado por el reconocimiento como pueblo, y que también tienen una agenda propia, porque ellas sostienen que "si trabajamos por las mujeres, para las mujeres, por los derechos de las mujeres... ipor supuesto que somos feministas!" (CLARIN,2016).

Otro reto a nivel metodológico, y de los más difíciles de tratar, gira en torno a identificar quiénes de las víctimas de feminicidio son afromexicanas ¿son quienes viven en un lugar reconocido como con alta población afrodescendiente? ¿qué hacer cuando se desconoce el autoreconociento como afromexicana, morena o negra? ¿qué hacer cuando no se tiene la información de la identidad de las víctimas? Resolver estas cuestiones sin duda tiene que hacerse en colaboración con las mujeres que están en terreno trabajando y organizándose.

En ese sentido, trabajo como el que realizan las mujeres de las Casas de Atención a la mujer Indígenas (CAMI), -particularmente la del Municipio de Ometepec, en la región de la Costa Chica de Guerrero-, que defienden los derechos de las mujeres indígenas y afromexicanas, es clave. La CAMI se cimenta en tres pilares: promotoras, parteras y jóvenes. Dentro de las promotoras han tenido a una joven afromexicana que ha colaborado en la Casa. Son ellas las que tienen el conocimiento de su territorio, de las comunidades y de la región; y están en varios frentes: el de sus propias comunidades y la institucional, acompañando a las mujeres indígenas $\mathrm{y}$ afromexicanas, cuando es necesario.

Ante el desconocimiento total del feminicidio de mujeres afromexicanas, negras o morenas, el fenotipo es un elemento clave, porque el llamarnos "negro" o "negra", por lo menos para quienes nacemos en la Costa Chica (de Guerrero o Oaxaca), tiene una carga racial que alude al fenotipo expresado en color de piel, forma de cabello y otros rasgos, que no necesariamente son discriminatorios. En la región, la identidad también pasa por lo físico, aun cuando no sea siempre lo determinante.

Es urgente el trabajo colaborativo, si queremos reconocer las voces diversas $\mathrm{y}$ reflexionar desde nuevas epistemologías, donde las propias mujeres, cuya condición racializada, de pobreza y de mujeres, pueden no recurrir, o pensar exclusivamente en las categorías centrales del feminismo (LOZANO, 2014), donde el entrecruce es la característica.

\section{Conclusiones}


A lo largo de este artículo he mostrado la invisibilización cuantitativa y cualitativa en algo tan básico como identificar los contextos y la situación del feminicidio de mujeres racializadas: las mujeres afromexicanas. Si los reportes del Secretariado Ejecutivo del Sistema Nacional de Seguridad Pública (SESNSP), donde se destaca que de enero a marzo del mismo año han sido asesinadas 720 mujeres en México (12 al día), no sabemos cuántas de ellas son indígenas, afromexicanas o negras.

La obligación de generar información confiable, en primer lugar, es de las instituciones del estado y sus agentes. Ya previamente mencioné por dónde comenzar: primero que esté claro en la normatividad el registro en el caso de feminicidio y homicidio de mujeres, la condición étnico-racial de mujeres indígenas y afromexicanas.

En el caso de las organizaciones que sistematizan el feminicidio, para identificar la identidad de las víctimas podemos recurrir a las técnicas de la Autopsia verbal, donde el trabajo con familiares de las víctimas, o personas cercanas, podremos saber la situación, característica, incluso la identidad, para trascender elementos como el fenotipo. La autopsia es una técnica utilizada "para identificar la magnitud de la mortalidad por causas específicas" (CÁRDENAS, 2000: 665), Si bien se define la causa de muerte, no la identidad ni la condición étnico- racial, podría ser una estrategia, mediante entrevistas personales, a la red de "actores que estuvieron cerca de la muerte acaecida y participaron en la secuencia de sucesos que condujeron a la misma" (ANDERSON, 2000, p. 29). La propuesta es hacer trabajo colaborativo con las mujeres organizadas afromexicanas, pero también con familiares directos, o personas cercanas de las mujeres asesinadas en regiones y localidades con población afrodescendiente.

Esto se propone porque en Guerrero y México, también existe la posibilidad de que la población no se asuma afrodescendiente por considerarlo como un concepto ajeno a su realidad; pero también están las organizaciones sociales que no se asumen negros o negras por su carga biologicista, cuestionando de esta forma el solo centrarse en rasgos físicos y apuestan por reconocerse como afromexicano/a. También está la población que asume con orgullo su color, tal como lo manifiesta la poeta afromexicana Aleida Violeta Vázquez Cisneros, de Cuajinicuilapa de Santa María, que dice en el poema "Nuestro color es grandeza". Por un lado, el fenotipo sigue siendo criterio para reconocerse en la comunidad, por otro, también sigue siendo marcador para discriminar, excluir, estereotipar, ejercer violencia y para pensar que ese cuerpo de mujer negra no vale, o vale menos que el de otras mujeres blancas o mestizas.

Si bien, la identidad no se reduce a 
fenotipo, tampoco hay que prescindir de él cuando las personas negras son propicias a ciertas violencias por la construcción estereotipada de la que han sido objeto históricamente: heterodesignadas como objetos sexuales, señaladas como "calientes", etc. Por ello, es imperativo reconocer que existen tipos de violencia que se ejerce contra las mujeres negras, por el hecho de ser mujeres negras, tanto por hombres dentro de la comunidad, como por hombres que están fuera de ella, y, sobre todo por las instituciones del Estado.

Entonces, cuando no se sabe absolutamente nada sobre la autoadscripción, o la condición étnico - racial de las víctimas de homicidio y feminicidio en Guerrero, los marcadores físicos son solo el punto partida. Otro elemento para considerar es el territorio donde ocurre el homicidio y feminicidio, por ejemplo, si es en municipio so localidad con alta proporción de población que se asume afrodescendiente, afromexicana o negra, en este sentido, el CENSO, 2020, nos dará más elementos de análisis.

Pero si como hemos visto, la prensa sigue siendo la fuente principal de información para organizaciones y académicas, a pesar de las bondades que brindan, también hay que reconocer metodológicamente las dificultades a las que nos enfrentan como personas interesadas para entender el feminicidio. Pongo por caso la descripción del asesinato, en
Cuajinicuilapa, de Gozo María de quien se reportó "La sacaron de la cantina de una señora de allí (de la colonia Miguel Alemán), a donde la mujer había ido a putear [cursivas propias] (AÑORVE 1, 2013, p. s/n)”.

Y, por otro lado, también se dijo:

Era domingo y ya habían llegado a ponerse [...] esas cantinas de güinsas (trabajadoras sexuales) ambulantes, [...], para la fiesta de la Candelaria, que comenzaría el siguiente miércoles. De uno de ellos la sacaron. Fue un hombre joven, dijeron. Ella había llegado de Cruz Grande (municipio con alta población afrodescendiente); era una chamaca, no pasaría de 25 años, dijeron.

Morena, de cabello chino, de buen cuerpo, aunque algo gordita, dijeron, bunitilla.

La sacaron de allí como a las tres de la tarde; eran las siete de la noche, y todavía no iban las autoridades a levantar el cuerpo (Añorve 2, 2013, p. s/n)

De este tamaño es el reto en la prensa, porque a pesar de que, al asesinato de Gozo María, si lo llaman feminicidio, la estereotipación e hipersexualización, es la característica visible. De un esfuerzo social, académico y político, depende que de Gozo se visibilice más allá que un cuerpo exuberante de "grandes" carnes, para reconocer las vulnerabilidades múltiples, como los marcadores de clase, género y étnico-racial que finalmente posibilitaron su asesinato, y es ahí donde el paradigma interseccional se hace necesario. 


\section{Referências bibliográficas}

AIKIN, Olga, "La agenda del" feminicidio" durante la Administración de Vicente Fox: Un estudio de caso en torno a la presión política transnacional'. Relaciones Internacionales: Revista académica cuatrimestral de publicación electrónica, 2012, no 19, p. 27-55.

ALCOCER, Marisol, Los motivos de Jano: ejercicio y contención de la violencia física, sexual y feminicidio contra mujeres en dos comunidades afromexicanas de la Costa Chica de Guerrero. Tesis para obtener el grado de Doctorado de Investigación en Ciencias Sociales, mención en Sociología, FLACSO, México, 2017.

ALCOCER, Marisol, "Ciudadanas de primera y segunda clase. Acercamiento al femicidio en guerrero y la jerarquización en el acceso a la justicia”. Revista Inclusiones, revista de Humanidades y Sociales, Universidad de los Lagos, Campus Santiago, Chile. ISSN 07194706 - Volumen 3 / Número 3 Julio septiembre 2016. Disponible en: http://www.archivosrevistainclusiones.com/gall ery/3\%20oficial\%202016\%20jul\%20sep\%20re v\%20inc.pdf

ALCOCER, Marisol, "Prostitutas, infieles y drogadictas." Juicios y prejuicios de género en la prensa sobre las víctimas de feminicidio: el caos de Guerrero, México.” Antípodas, Revista de antropología y arqueología, No. 20, septiembre-diciembre 2014, Bogotá, pp. 97 118.

ALIANZA DE MUJERES FEMINISTAS, Diagnóstico sobre el estado que guarda la violencia feminicida en Guerrero. Guerrero, (informe proporcionado por la peticionaria, Licenciada Marina Reyna Aguilar), 2016.

ANDERSON, J., et al. Mujeres de negro: la muerte materna en zonas rurales del Perú, estudio de casos. Lima: Ministerio de Salud, 1999.

BUTLER, Judith, Vida precaria. El poder del duelo y la violencia. Buenos Aires: Paidós, 2009.
CÁRDENAS, Rosario. "El uso de la autopsia verbal en el análisis de la salud. Estudios demográficos y urbanos", 2000, p. 665-683.

CÁMARA DE COMERCIO DE BOGOTÁ, OPEN SOCIETY FOUNDATIONS, FISCALÍA GENERAL DE LA NACIÓN, MINISTERIO DE JUSTICIA Y DEL DERECHO, LABORATORIO DE ANÁLISIS DE LA VIOLENCIA DE LA UNIVERSIDAD DEL ESTADO DE RÍO DE JANEIRO, Protocolo de Bogotá sobre calidad de los datos de homicidio en América Latina y el Caribe. Fecha, 2015-11-03. Disponible en https://bibliotecadigital.ccb.org.co/handle/11520 $/ 14026$

CATÓLICAS POR EL DERECHO A DECIDIR, Y COMISIÓN MEXICANA DE DEFENSA Y PROMOCIÓN DE LOS DERECHOS HUMANOS, A.C. Informe Feminicidio e impunidad en México: Un contexto de violencia estructural y generalizada. México. Informe presentado ante el Comité para la Eliminación de la Discriminación contra la Mujer, CEDAW. [Última consulta, 25-072012, http://www.cmdpdh.org/docs/Informe_Feminici dio_Cedaw_16_07_2012.pdf]

COMISIÓN ESPECIAL PARA CONOCER Y DAR SEGUIMIENTO A LAS

INVESTIGACIONES RELACIONADAS CON LOS FEMINICIDIOS EN LA REPÚBLICA MEXICANA Y LA JUSTICIA VINCULADA DE LA CÁMARA DE DIPUTADOS DEL H. CONGRESO DE LA UNIÓN LIX LEGISLATURA, Informe Violencia Feminicida En 10 Entidades de la República. México: Cámara de Diputados, 2006.

COMISIÓN ESPECIAL PARA CONOCER Y DAR SEGUIMIENTO A LAS

INVESTIGACIONES RELACIONADAS CON LOS FEMINICIDIOS EN LA REPÚBLICA MEXICANA Y LA JUSTICIA VINCULADA DE LA CÁMARA DE DIPUTADOS DEL H. CONGRESO DE LA UNIÓN LIX LEGISLATURA. Informe Violencia Feminicida en Guerrero, México: H. Congreso de la Unión, 2006. 
CONAVIM, Informe de Grupo de trabajo para atender la solicitud de Alerta de Género contra las Mujeres en Ocho municipios del Estado de Guerrero. 2016. Última consulta 18-10-2016, disponible en:

https://www.gob.mx/cms/uploads/attachment/fil e/127431/Informe_AVGM_Guerrero.pdf

\section{CONSTITUCIÓN POLIITICA DEL ESTADO} LIBRE Y SOBERANO DE GUERRERO, disponible en

http://congresogro.gob.mx/62/legislacion/ última consulta 08 de junio de 2020.

CURIEL, Ochy, "Los aportes de las afrodescendientes a la teoría y la práctica feminista. Desuniversalizando el sujeto "mujeres", Publicado en: Perfiles del Feminismo Iberoamericano, vol. III, Buenos Aires, Catálogos. 2007.

DATA CÍVICA, Claves para entender y prevenir los asesinatos de mujeres en México. DATA CÍVIA, OPEN SOCIETY FOUNDATIONS, Derechos sexuales y Reproductivos- Programa de Derecho a la Salud -CIDE. Última consulta 19- 06- 2020. Disponible en https://datacivica.org/contenido

EL PAIS, "México pregunta por primera vez sobre la población negra y afrodescendiente", disponible en:

https://elpais.com/sociedad/2020-03-02/mexicopregunta-por-primera-vez-sobre-la-poblacionnegra-y-afrodescendiente.html Última consulta 01 de junio de 2020

ENCUESTA INTERCENSAL, "Principales resultados". INEGI, 2015. Disponible en https://www.inegi.org.mx/programas/intercensa 1/2015/ última consulta 26-06-2020.

FIGUEROA, Dolores. "Políticas de Feminicidio en México: Perspectivas interseccionales de mujeres indígenas para. reconsiderar su definición teórica-legal y las metodología de recolección de datos". Journal of International Women's Studies, 2019, vol. 20, no 8, p. 64-86.

FLYVBJERG, Bent "Cinco malentendidos acerca de la investigación mediante los estudios de caso." Revista Española de Investigaciones Sociológicas, 2004, 106: 33-62.

FOUCAULT, Michel. El orden del discurso. Madrid: Letra E, 1992.

\section{GOBIERNO DEL ESTADO DE}

GUERRERO, Protocolo de Investigación Ministerial, Policial Y Pericial con Perspectiva de Género para el Delito de Feminicidio, Disponible en:

http://www.guerrero.gob.mx/consejeriajuridica, publicado en 2017. Última consulta 25 de junio de 2020. Gobierno del Estado de Guerrero.

HARDING, Sandra, “'existe un método feminista?", en Bartra, Eli. En torno a una metodología feminista, D.F, Universidad Autónoma Metropolitana-Xoxhimilco, 2002.

HOFFMANN, O. y LARA, G. (2012).

"Reivindicación afromexicana: formas de organización de la movilización negra en México". En M. J. BECERRA, D. Buffa, H. Noufouri y M. Ayala (Comps.), Las poblaciones afrodescendientes de América Latina y el Caribe. Pasado, presente y perspectivas desde el siglo XXI (pp. 25-46). Córdoba: Universidad Nacional Tres de Febrero-Centro de Estudios Avanzados de la Universidad Nacional de Córdoba, Programa de Relaciones Internacionales y Estudios Africanos del Centro de Investigaciones y Estudios sobre Cultura y Sociedad y la Cátedra UNESCO.

Instituto de Liderazgo Simone de Beauvoir, Declaratoria de Mujeres Afromexicanas de la Costa Chica, Disponible en: http://ilsb.virk.io/foro_mujeresafro/ última consulta 01 de junio de 2020.

\section{LAGARDE Y DE LOS RÍOS, Marcela,} "Antropología, feminismo y política: violencia feminicida y Derechos Humanos de las Mujeres", 2011, Retos teóricos y nuevas prácticas. XI Congreso de Antropología: retos teóricos y nuevas prácticas. Pp- 209- 239, ISBN13-978-84-691-4952-2. Disponible en: http://hedatuz.euskomedia.org/5336/1/1420923 9.pdf última consulta 20-02-2015

LAURENZO COPELLO, Patricia, "Apuntes sobre el feminicidio", UNED. Revista de 
Derecho Penal y Criminología, $3^{\text {a }}$ Epoca, no. 8. 2012.

\section{LEY ORGÁNICA DE LA FISCALÍA GENERAL DEL ESTADO DE GUERRERO NÚMERO 500, disponible en} https://www.google.com/url?sa=t\&rct=j\&q=\&e $\mathrm{src}=\mathrm{s} \&$ source $=$ web $\& \mathrm{~cd}=\& \mathrm{cad}=\mathrm{rja} \& u a c t=8 \& \mathrm{ve}$ $\mathrm{d}=2 \mathrm{ahUKEwiMtbSrpPfpAhUMP60KHeNeAt}$ EQFjAAegQIARAB\&url=http $\% 3 \mathrm{~A} \% 2 \mathrm{~F} \% 2 \mathrm{Fw}$ ww.cnpj.gob.mx\%2Fnormatividad\%2FDocum entos_Normatividad\%2FLey\%2520Org\%25C3 $\% 25 \mathrm{~A} 1$ nica\%2520de\%2520la\%2520Fiscal\%25 C3\%25ADa\%2520General\%2520del\%2520Est ado\%2520de $\% 2520$ Guerrero.pdf\&usg=AOvVa w2K3JAOwy7m-djAxDy877pu

LÓPEZ BONILLA, Guadalupe y PÉREZ FRAGOSO, Carmen, "Discurso", en AZURMUK, Mónica, y MCKEE IRWIN, Robert, Diccionario de Estudios Culturales latinoamericanos. México, Siglo XXI Editores e Instituto Mora, 2009.

MARTÍN, Dale y Margo WILSON. "Hasta que la Muerte nos separe". En Diana Russell y Jill Radford Feminicidio. La política del asesinato de las mujeres, eds., pp 179-236. Distrito Federal., CEIICH-UNAM2006.

MARTÍN, Dale y WILSON, Margo "Hasta que la Muerte nos separe". En MARTÍNEZ DE LA ESCALERA, Ana María, Feminicidio: actas de denuncia y controversia. México: PUEG, 2006.

MELGAR, Lucía, "Tolerancia ante la violencia, feminicidio e impunidad (algunas reflexiones)", en HUACUZ Elías, María Guadalupe, (coord.) La bifurcación del caos. Reflexiones interdisciplinarias sobre violencia falocéntrica. D.F.: Universidad Autónoma MetropolitanaXochimilco, 2011.

MONÁRREZ FRAGOSO, Julia, Trama de una injusticia. Feminicidios sexuales sistémico en Ciudad Juárez, D.F, Porrúa-COLEF, 2009.

MONÁRREZ FRAGOSO, Julia. "Feminicidio sexual serial en Ciudad Juárez: 1993-2001". Debate feminista, 2002, vol. 25, p. 279-305.

OJEDA, Rosa Icela, Informe de homicidios dolosos de mujeres del estado de Guerrero,
2005- 2016. Acapulco: OVICOM-UAGRo, 2017.

RADFORD, Jill, “Introducción”, pp. 33-52 en RUSSELL. E. Diana y RADFORD, Jill. Feminicidio. La política del asesinato de las mujeres. D.F: CEIICH- UNAM, 2006.

SCOTT, Joan W. "Igualdad versus diferencia: los usos de la teoría postestructuralista." Debate feminista, 1992, vol. 5, p. 85-104.

SEGATO, Laura Rita, Las nuevas formas de la guerra y el cuerpo de las mujeres. $1^{a}$ Edición. Puebla: Pez en el árbol, 2014.

SEGATO, Rita Laura. Que es un feminicidio: notas para un debate emergente. Brasil: Universidad de Brasilia, Departamento de Antropología, 2006.

SEGOB, ONUMUJERES, INMUJERES, Informe, Feminicidio en México. Aproximación, tendencias y cambios, 1985-2016. Algunos elementos para un diagnóstico del feminicidio en el estado de Guerrero. México: SEGOB, Secretaría de Gobernación, INMUJERES, Instituto Nacional de las Mujeres, (C) ONU Mujeres, Entidad de las Naciones Unidas para la Igualdad de Género y el Empoderamiento de las Mujeres, 2017.

SENADO DE LA REPÚBLICA, "Senado realizará actividades culturales para enaltecer a los pueblos afromexicanos", Disponible en http://comunicacion.senado.gob.mx/index.php/i nformacion/boletines/47577-senado-realizaraactividades-culturales-para-enaltecer-a-lospueblos-afromexicanos.html última consulta 15 de mayo de 2020

SESIA, P. M. Diagnóstico de la situación de las mujeres afrodescendientes en la Costa de Oaxaca México. Oaxaca. Oaxaca: INMUJERES -IMO, 2013.

VAN DIJK, Teun. "El racismo de la élite". Archipiélago, (Barcelona), 14, 1993, pp. 106111.

WAISELFISZ, Julio Jacobo. Mapa da violência 2015: homicídio de mulheres no Brasil. Brasil. Brasil: Flacso Brasil, 2015. 


\section{Fuente hemerográfica}

AGUSTÍN ESTEBAN, Rogelio, "Reconocen autoridades que en Guerrero existe alto índice de asesinatos de mujeres", Periódico El Sol de Acapulco. Acapulco, Gro. Martes 13 de septiembre de 2005.

CLARIN, "Mujeres Guerreras Mujeres afromexicanas: cuando la negritud va más allá del color de la piel", disponible en https://www.clarin.com/entremujeresmexico/genero/mujeres_afromexicanasmexicanas_negras-mujer_negradiscriminacion-afro_0_HksXvOpC.html última consulta 10 de junio de 2020.

CERVANTES, Zacarías, "En Guerrero, los asesinatos de mujeres no son por misoginia: Nogueda Carvajal". El Sur, en "sección Guerrero", 19 de marzo de 2005.

CRUZ, Salomón, "Hay sólo 3 casos de feminicidios en Guerrero, asegura la fiscal Especializada en ese delito", IRZA, 25 de julio de 2011.

ESTEBAN AGUSTÍN, Rogelio, "Rechaza Guerrero repunte de feminicidios" Milenio, en "Sección Estados", 22 de julio de 2012.

FLORES CONTRERAS, Ezequiel, "Demandan directivos de la Prepa 33 se investigue el crimen de la joven quemada en Chilpancingo", El Sur, en "Sección Guerrero", 4 y 5 de marzo de 2006, pp. 31.

GARCÍA, Eva, “¿Qué más tenemos que ver?” El Sol de Acapulco. 18 de marzo de 2004.

GONZÁLEZ, Benicio, Carmen "Porque le fue infiel, un indígena asesinó a su esposa en Tlapa frente a sus tres hijos", El Sur, en "página 9", 4 de julio de 2007.

PELÁEZ, Aurelio, “Evocan a Ciudad Juárez y piden atender con puntualidad los asesinatos de mujeres en Acapulco", El Sur, "Acapulco", 12 de diciembre de 2003.
NAVA, Jorge, "Califica el fiscal especial de "aislados" los casos de mujeres asesinadas", El sur: Guerrero. 19 de diciembre de 2003.

OJEDA RIVERA, Rosa Icela, "Feminicidios, inequidad e injusticia”, El Sur Acapulco: Opinión. 10 de mayo de 2005

TORRES, Ana Lilia, "Darán a conocer información sobre crímenes contra mujeres", El Sol de Acapulco. 21 de enero de 2004.

ZAMORA, Elsa, "Recuento final de mujeres asesinadas en Guerrero", El Sol de Acapulco. 4 de enero de 2004.

AÑORVE, Eduardo, "En El Pitahayo mataron a una mujer enamorada", Blogspot, Noticias desde cuajinicuilapa y otros temas. 2013, Última consulta, 07-01-2017, disponible en: http://cuaje.blogspot.mx/search/label/Feminicidi o

AGENTE DEL ESTADO 1, [entrevista] por Marisol Alcocer [trabajo de campo], La representación de las víctimas de feminicidio en la prensa guerrerense, 2005-2009, Guerrero, 2012.

NENGO, [Entrevista] por Marisol Alcocer Perulero [trabajo de campo], Los motivos de Jano: ejercicio y contención de la violencia física, sexual y feminicidio contra mujeres en dos comunidades afromexicanas de la Costa Chica de Guerrero, 2017. 